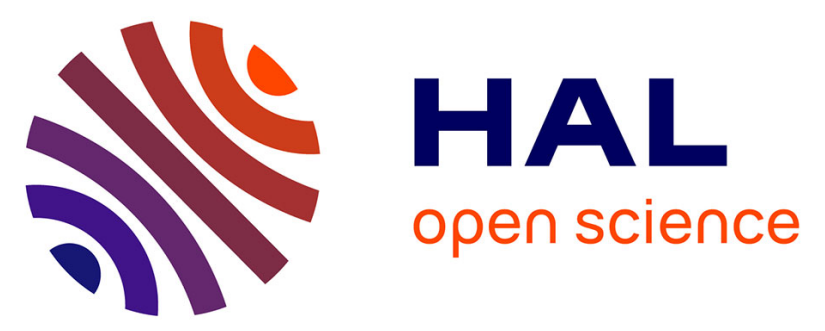

\title{
Superficial middle cerebral vein connection to the cavernous sinus is not infrequent in brain arteriovenous malformations: an argument against their congenital origin?
}

Eimad Shotar, Alexis Guédon, Nader Sourour, Federico Di Maria, Joseph Gabrieli, Aurélien Nouet, Jacques Chiras, Frédéric Clarençon

\section{To cite this version:}

Eimad Shotar, Alexis Guédon, Nader Sourour, Federico Di Maria, Joseph Gabrieli, et al.. Superficial middle cerebral vein connection to the cavernous sinus is not infrequent in brain arteriovenous malformations: an argument against their congenital origin?. Neuroradiology, 2016, 10.1007/s00234016-1679-9 . hal-01301012

\section{HAL Id: hal-01301012 https://hal.sorbonne-universite.fr/hal-01301012}

Submitted on 11 Apr 2016

HAL is a multi-disciplinary open access archive for the deposit and dissemination of scientific research documents, whether they are published or not. The documents may come from teaching and research institutions in France or abroad, or from public or private research centers.
L'archive ouverte pluridisciplinaire HAL, est destinée au dépôt et à la diffusion de documents scientifiques de niveau recherche, publiés ou non, émanant des établissements d'enseignement et de recherche français ou étrangers, des laboratoires publics ou privés. 
Superficial Middle Cerebral Vein Connection to the Cavernous

Sinus is Not Infrequent in Brain Arteriovenous Malformations:

an Argument Against Their Congenital Origin?

Eimad Shotar (1), Alexis Guédon (1), Nader Sourour (1), Federico Di Maria (1), Joseph Gabrieli (1) (2), Aurélien Nouet (3), Jacques Chiras (1) (2), Frédéric Clarençon (1) (2) [fredclare5@msn.com]

1. Department of Interventional Neuroradiology, Pitié-Salpêtrière Hospital, 47, Boulevard de l'Hôpital, 75013, Paris, Fran

2. Paris VI University, Pierre et Marie Curie, Paris, France

3. Department of Neurosurgery, Pitié-Salpêtrière Hospital, Paris, France 


\section{Abstract}

PURPOSE: The aim of this study was to test the hypothesis that the superficial middle cerebral vein (SMCV) is frequently absent or fails to connect with the cavernous sinus (CS) in presence of brain AVMs, a frequently reported argument for the congenital origin of brain AVMs.

METHODS: The SMCV was retrospectively compared between patients with a brain $\mathrm{AVM}$ and a control group. The presence or absence of the SMCV, its direct or indirect connection to the CS and its termination in a laterocavernous sinus (LCS), paracavernous sinus (PCS) or directly in the CS was studied on digital subtraction angiography.

RESULTS: 125 left or right side carotid angiograms from 70 patients with a brain AVM were compared to 125 angiograms from 74 controls. The SMCV was present in $88(70.4 \%)$ cases in the brain AVM group and $96(76.8 \%)$ cases in controls $(p=0.25)$. The SMCV was connected directly or indirectly to the CS in $65(52 \%)$ cases in the brain AVM group and $65(52 \%)$ cases in controls $(p=1)$. When comparing the subgroup of carotid angiograms ipsilateral to a supratentorial AVM, no statistically significant difference was found with controls. In 3/6 cases in which a SMCV drained an AVM, the vein terminated directly or indirectly in the CS.

CONCLUSIONS: No difference of SMCV presence and direct or indirect connection to the CS was found between patients with AVM and a control group. SMCV anatomy does not support the congenital origin of brain AVMs. 
Key words: anatomy; arteriovenous malformations; congenital origin; postnatal development; superficial middle cerebral vein; connection

Abbreviations and acronyms:

AP: Anteroposterior

CS: Cavernous Sinus

LCS: Laterocavernous Sinus

PCS: Paracavernous Sinus

PP: Pterygoid Plexus

SMCV: Superficial Middle Cerebral Vein

SPS: Superior Petrosal Sinus 


\section{Introduction}

AVMs are rare vascular malformations characterized by an abnormal connection between arteries and veins through a network of tangled and tortuous vessels: the so-called nidus. Brain AVMs have an annual detection rate of roughly 1 per 100000 in prospective population-based studies $[1,2]$ and are a leading cause of stroke in young adults [2].

Brain AVMs have been thought to be congenital in nature [3, 4]. In 1996, Mullan et al. hypothesized that brain AVMs were possibly formed in utero during the 40 to $80 \mathrm{~mm}$ stage [5]. They stated that the frequent absence or anomaly of the middle cerebral vein and its failure to communicate with the cavernous sinus in the presence of both cerebral venous malformations and AVMs are linked to the late development of that vein and to its even later connection to the cavernous sinus [5]. As the connection of the superficial middle cerebral vein (SMCV) with the cavernous sinus (CS) is thought to be postnatal [6], failure of the SMCV to connect with the CS in presence of a brain AVM could be an argument for their congenital nature. This reminds of vein of Galen aneurysmal malformations. Indeed, vein of Galen aneurysmal malformations are true congenital vascular arteriovenous shunts with a persistent median prosencephalic vein and are associated with failure of the deep venous system to reach adult configuration [7].

Several recent observations contradict the long-held dogma that brain AVMs are congenital lesions. Antenatal ultrasound and MRI have dramatically increased prenatal detection of fetal malformations, among which vein of Galen aneurysmal malformations and dural sinus malformations [8]. However, prenatal detection of pial arteriovenous shunts remains exceedingly rare and to date, only cases of non-nidal 
fetal pial arteriovenous fistulas have been reported [9-12]. Only $20 \%$ of brain AVMs are revealed during childhood, raising the question of why most brain AVMs clinically manifest during adulthood if they are congenital and present from birth [13]. Several reports of de novo brain AVMs have been documented on serial angiographies and MRIs, demonstrating the potential for postnatal onset [14]. Finally, experimental studies have shown de novo brain AVM development to be possible after Eng or Alk1 deletion and angiogenic stimulation in adult mice $[15,16]$.

Although having been published about 20 years ago, the original report by Mullan et al. [5] has never been contradicted and continues to be regularly cited as an argument for the congenital origin of brain AVM [3, 17-19]. The aim of our study was to test Mullan's statement that the SMCV is frequently absent or fails to connect with the CS in presence of brain AVM. 


\section{Methods}

\section{Study population}

A retrospective review of medical records of patients with brain AVM managed at our institution was undertaken. A list of consecutive patients with a diagnosis of ruptured or unruptured brain AVM on DSA was generated by searching discharge databases of interventional neuroradiology, neurosurgery, neurosurgical intensive care and neurology departments. We screened adult patients with DSA performed from September 1, 2007, to December 31, 2014. Patients previously treated for their brain AVM were excluded. The control group was composed of patients admitted at the same Institution for ruptured or unruptured intracranial aneurysms from January 1, 2014, to December 31, 2014. Age, gender and past history of brain AVM or aneurysm rupture were recorded.

\section{$D S A$ and image analysis}

All patients underwent DSA using a standard femoral approach under local or general anesthesia in a biplane angiography suite (Axiom Artis, Siemens, Erlangen, Germany). Images were acquired at a frame rate of two or six images per second. Unilateral or bilateral carotid studies were generated with venous phase in anteroposterior (AP) and lateral projections in all patients. Oblique projections were generated in most patients. The imaging studies were independently reviewed by a junior (ES or $A G$ ) and a senior (FC) interventional neuroradiologist blinded to the clinical data of the patient. The following data were recorded by both readers: presence or absence of a SMCV, duplicated SMCV, direct or indirect (through a laterocavernous sinus [LCS] or paracavernous sinus [PCS]) connection of the SMCV 
to the CS, presence of a brain AVM ipsilateral to the SMCV and drainage of the brain AVM into the SMCV. The termination of the SMCV into a LCS, PCS or directly into the CS and the drainage of the LCS or PCS into the CS, pterygoid plexus (PP), superior petrosal sinus (SPS) or tentorial sinus were recorded as previously described [20]. Discrepancies were settled by joint discussion by the two readers. For patients with a bAVM, we have chosen, when DSAs were available, to include both side (i.e.: ipsilateral and contralateral to the bAVM) in the group "bAVM" since venous outflows are interrelated and an abnormality of one part will often influence the evolution of others [21]. We also compared the subgroup of carotid angiograms ipsilateral to supratentorial brain AVMs with control group DSAs.

In order to better understand the close spatial relationship between the different vascular structures studied, fusion images were generated. These images for the figures were generated using an open-source software (GIMP, version 2.8, available at http://www.gimp.org/). The grey scale of one of the two images to be superimposed was inverted. Transparency was modified until both images were adequately visible. When fusing images of different phases (arterial and venous) of a single carotid angiogram in the same patient, no manipulation for registration was necessary. For fusing of different angiograms (right and left sides) of a single patient, the superior sagittal sinus, transverse sinuses and sigmoid sinuses were used as references for accurate registration.

\section{Statistical analysis}

All statistical analyses were performed using a commercially available software package (Stata, StataCorp, Texas, USA). All variables were considered independent. 
Categorical data are presented as proportions and continuous variables are presented as mean \pm standard deviations. The interobserver reliability for determining the SMCV anatomy on DSA was assessed by calculation of $\kappa$ values. The $\kappa$ values were categorized as previously reported [22] : $\kappa=0.41$ to $0.6,0.61$ to 0.8 , and 0.81 to 1 indicate moderate, good, and excellent agreement between observers, respectively. $A \kappa=1$ indicates total agreement between observers. Comparisons of the brain AVM and control groups were performed on a merged data set after discrepancies were settled by joint discussion by the two readers. The demographic and radiological characteristics were compared between patients with a brain AVM and controls by using Chi-squared test, Fisher's exact test, and student $t$ test as appropriate. A $p<0.05$ was considered statistically significant. A Bonferroni's correction was applied for subgroup analysis (3 types of SMCV's connection to the CS) with an adjusted statistical significance threshold of $p<0.016(0.05 / 3=0.016)$. In a second analysis, radiological characteristics were compared between angiograms with an ipsilateral supratentorial brain AVM and controls.

\section{Ethical statement}

Neither approval of the institutional review board nor patient informed consent are required by the ethics committee of our institution for retrospective analyses of patients' records and imaging data. 


\section{Results}

One hundred and fifty patients with a total of 275 right or left side carotid angiograms were screened for this study. SMCV's anatomy was deemed not interpretable in 25 angiograms (motion artifacts in 13 cases, venous phase not available in 8, inadequate subtraction in 3 and vasospasm in 1 case) and were thus excluded (leading to exclusion of 6 patients, either because bilateral angiograms were deemed not interpretable in 5 patients or because the only available angiogram was deemed not interpretable for 1 patient). Seventy patients with 125 angiograms (55 patients with bilateral angiograms, 10 patients with only right sided angiograms and 5 patients with only left sided angiograms) were included for analysis in the brain AVM group. Seventy-four patients with 125 angiograms (51 patients with bilateral angiograms, 14 patients with only right sided angiograms and 9 patients with only left sided angiograms only) were included in the control group. Mean age was $41 \pm 15$ years (51\% males) in the brain AVM group and $50 \pm 13$ years ( $30 \%$ males) in the control group (Table 1).

All angiograms were analyzed by two of the study authors. For determining whether the SMCV was present or absent, and when present if it was connected directly or indirectly to the CS, the inter-rater agreement was good $(\kappa=0.71 ; 95 \% \mathrm{Cl}=0.64$ to 0.79). For determining whether the SMCV was present or absent, and, when present, its mode of termination into a LCS, PCS or directly into the CS, the inter-rater agreement was moderate $(\kappa=0.59 ; 95 \% \mathrm{Cl}=0.51$ to 0.66$)$.

All variants of the SMCV termination were observed, including absence of SMCV (Fig. 1), direct termination of the SMCV in the CS (Fig. 2), termination in a LCS (Fig. 2) and termination in a PCS (Fig. 3). There was no difference in terms of presence or 
absence of the SMCV between the brain AVM and control groups (Table 1). Moreover, when present, the SMCV direct or indirect (through a LCS or PCS) connection to the CS was not significantly different between the two groups. No difference was observed regarding SMCV termination into a LCS or directly into the CS between the brain AVM and the control group (Table 1). However, the SMCV terminated into a PCS less frequently in the brain AVM group than in the control group ( $p$-value $=0.02)$ but this difference was no longer statistically significant when applying a Bonferroni's correction $(0.05 / 3=0.016)$.

In a second analysis, all carotid angiograms ipsilateral to supratentorial brain AVMs (53 patients with 53 angiograms) were compared to the control group (74 patients with 125 left and/or right side angiograms) (Table 2). No statistically significant difference was found in terms of SMCV anatomy between the two groups.

In 6 out of 70 patients, a brain AVM was found to be drained completely or partly through a SMCV. In 2 cases, the SMCV directly terminated in the CS (Fig. 4). In 1 case, the SMCV terminated in a LCS that drained in the CS and PP. In 2 cases, the SMCV terminated in a PCS that drained in the SPS Finally, in 1 case, the SMCV terminated in a LCS that drained only in the SPS. Thus, in 3 out of 6 cases $(50 \%)$, a SMCV draining a brain AVM terminated directly or indirectly in the CS.

Hemorrhagic presentation is a potential source of bias as it may obscure the SMCV. Therefore, we sought to compare SMCV anatomy between patients with and without hemorrhagic presentation. In the AVM group, the SMCV was found to be present in $67 / 96(69.8 \%)$ sides in patients with a hemorrhagic presentation (54/70 patients, $77.1 \%)$ and in $21 / 29(72.4 \%)$ sides in patients without hemorrhagic presentation (16/70 patients, $22.9 \%$ ) ( $p$-value=0.97). When present, the SMCV connected directly 
or indirectly to the CS in 48/96 (50\%) sides in the ruptured brain AVM group and in $17 / 29(58.6 \%)$ sides in the non-ruptured brain AVM group ( $p$-value=0.55). In the control group, the SMCV was found to be present in $54 / 74(73 \%)$ sides in patients with hemorrhagic presentation (45/74 patients, $60.8 \%)$ and $42 / 51$ (82.4\%) sides in patients without hemorrhagic presentation $(29 / 74$ patients, $39.2 \%)(p$-value $=0.31)$. When present, the SMCV connected directly or indirect to the CS in $36 / 74(48.6 \%)$ sides in the control group with hemorrhagic presentation and 29/51 (56.9\%) sides in the control group without hemorrhagic presentation ( $p$-value=0.47).

\section{Discussion}

A SMCV draining a brain AVM and terminating in the CS has previously been reported [23]. However, our work is, to the best of our knowledge, the first systematic study of the SMCV anatomy in a group of patients with brain AVMs compared to a control group.

The SMCV is a supratentorial cerebral vein coursing along the lateral sulcus and connected caudally to the superior anastomotic vein of Trolard and/or to the inferior anastomotic vein of Labbé. Its cranial termination has long been assimilated to the sphenoid portion of the sphenoparietal sinus of Breschet. This notion has been challenged by San Millan Ruíz et al., who have shown that the so called sphenoparietal sinus corresponds to the artificial combination of two venous structures: a dural sinus coursing under the lesser sphenoid wing and the parietal portion of the anterior branches of the middle meningeal veins [24]. They have further shown that the sinus of the lesser sphenoid wing was connected laterally to the anterior branch of the middle meningeal veins and medially to the cavernous sinus, but never to the SMCV [24]. In another study, San Millan Ruíz et al. have also 
demonstrated the existence of a venous structure within the two dural layers forming the lateral wall of the cavernous sinus which they termed the LCS [25]. According to these authors, the termination of the SMCV can follow three distinct patterns: 1) direct termination into the anterosuperior aspect of the CS; 2) termination within the lateral wall of the CS in what is called a LCS; or 3) following a lateral trajectory within the dural floor of the middle cranial fossa, taking the name of PCS $[20,25]$. The LCS can have three distinct draining patterns: 1) towards the ipsilateral transverse sinus via the SPS; 2) towards the PP through middle cranial fossa foramina; or 3) towards the posterior aspect of the CS, all of which can be angiographically demonstrated [20]. The drainage pathways towards the SPS and the PP are similar to the drainage patterns described for the PCS as sphenopetrous and sphenobasal sinuses, respectively [20]. Gailloud et al. have found the SMCV to be absent in $19 \%$ of the cases. When present, they found the SMCV terminating directly in the CS in $20 \%$ of cases, in a PCS in $39 \%$ of cases and in a LCS in $22 \%$ of cases [20]. Compared to these previous results, we found a larger proportion of SMCV terminating in a LCS (24.8\% in the control group and $30 \%$ in the overall population) and a smaller proportion terminating directly in the CS $(17.6 \%$ in the control group and $15.6 \%$ in the overall population) and in a PCS $(34.4 \%$ in the control group and $28 \%$ in the overall population).

Age and sex ratio were different in the brain AVM and control groups. This was to be expected given that brain AVMs are usually discovered at a younger age and, contrary to brain AVM, intracranial aneurysms are more frequent in women than in men $[2,26]$. To the best of our knowledge, SMCV anatomy does not vary at adult age or between men and women. However, we found no report in the literature specifically directing this issue. Moreover, hemorrhagic presentation was more 
frequent in the brain AVM group as compared to the control group, which is related to specificity of patient referral in the study center. We have not shown any statistically significant difference between patients with a brain AVM and those from the control group regarding absence or presence of the SMCV. Furthermore, no difference was found regarding the proportion of direct and indirect connection of the SMCV to the CS. This result contradicts previous reports and consequently the hypothesis that brain AVMs have a congenital origin [5, 27].

As indicated above, recent observations contradict the congenital origin of brain AVMs, stressing the need for new models to explain brain AVM development. New insight into pathogenesis of this disease has been provided by animal models based on deletion of Eng or Alk1 genes, implicated in hereditary hemorrhagic telangiectasia type 1 and 2, respectively. Most strikingly, deletion of these genes in adult mice, in combination with local "Vascular Endothelial Growth Factor" stimulation, leads to brain AVM development $[15,16,28]$. These works have lead to propose the « response-to-injury » paradigm to explain brain AVMs' pathogenesis [29]. In this model, brain AVMs are considered an exuberant dysplastic response of a vulnerable vascular segment to an pro-angiogenic stimulus. Vulnerability may be genetic or anatomic. The inciting event might be mechanical, ischemic, a somatic second hit mutation or any other phenomenon stimulating angiogenesis. To date, this model represents the most satisfactory explanation to brain AVMs' pathogenesis. Furthermore, the « response-to-injury » paradigm does not necessarily regard brain AVMs as congenital lesions. Indeed, vulnerability, whether anatomical or genetic, may be prenatal while onset of the brain AVM following injury may be postnatal. 


\section{Limitations:}

Several limitations undermine the results of our study including retrospective design, small sample size and referral bias influencing demographic and clinical characteristics of the patient cohort [30]. The control group was not composed of healthy individuals but instead patients managed for intracranial aneurysms. It has been reported that venous hypertension may be implicated in aneurysm rupture [31]. However, contrary to perimesencephalic nonaneurysmal hemorrhage [32], there is, to the best of our knowledge, no evidence of venous anatomical variations in patients harboring intracranial aneurysms. Moreover, since the advent of non-invasive brain imaging modalities, DSA is usually reserved to patients with known neurovascular disease, limiting the possibility to constitute a control group of healthy individuals. Hemorrhage is a potential source of bias by obscuring the SMCV. However, no statistically significant difference was found between patients with and without hemorrhagic presentation, either in the brain AVM group or the control group. The study was not restricted to brain AVM draining in the SMCV. This would have required a much larger brain $\mathrm{AVM}$ cohort, difficult to assemble given the low prevalence of brain AVMs. However, Mullan et al. [5] do not restrict their observation to this subset of patients and instead describe frequent absence of SMCV and failure to connect to the CS in the general setting of brain AVM. Moreover, in 3 out of 6 cases in which the AVM drained via the SMCV in our study population, the vein terminated directly or indirectly in the CS. While this study does suggest that the theory implicating the absence of a SMCV or the lack of connection to the cavernous sinus is probably not associated with brain AVM development, it does not necessarily follow that other differences in venous anatomy might not point to a congenital origin. Further work comparing general venous anatomy between brain AVM patients and 
controls is needed to clarify this point. Finally, the result of this study does not directly contradict the congenital origin of brain AVM but instead only challenge a frequently reported argument for congenital origin [3, 17-19]. 


\section{Conclusions}

We did not find any difference in terms of presence of a SMCV and connection to the CS between patients with a brain AVM and a control group. SMCV anatomy does not support the congenital origin of brain AVM. 
Conflict of Interest

We declare that we have no conflict of interest. 


\section{References}

1. Al-Shahi R, Bhattacharya JJ, Currie DG, et al. (2003) Prospective, populationbased detection of intracranial vascular malformations in adults: the Scottish Intracranial Vascular Malformation Study (SIVMS). Stroke J Cereb Circ 34:1163-1169. doi: 10.1161/01.STR.0000069018.90456.C9

2. Stapf C, Mast H, Sciacca RR, et al. (2003) The New York Islands AVM Study: design, study progress, and initial results. Stroke J Cereb Circ 34:e29-33. doi: 10.1161/01.STR.0000068784.36838.19

3. Fleetwood IG, Steinberg GK (2002) Arteriovenous malformations. Lancet 359:863-873. doi: 10.1016/S0140-6736(02)07946-1

4. Friedlander RM (2007) Clinical practice. Arteriovenous malformations of the brain. N Engl J Med 356:2704-2712. doi: 10.1056/NEJMcp067192

5. Mullan S, Mojtahedi S, Johnson DL, Macdonald RL (1996) Embryological basis of some aspects of cerebral vascular fistulas and malformations. J Neurosurg 85:1-8. doi: 10.3171/jns.1996.85.1.0001

6. Padget $\mathrm{DH}$ (1956) The cranial venous system in man in reference to development, adult configuration, and relation to the arteries. Am J Anat 98:307355. doi: 10.1002/aja.1000980302

7. Lasjaunias P, Garcia-Monaco R, Rodesch G, Terbrugge K (1991) Deep venous drainage in great cerebral vein (vein of Galen) absence and malformations. Neuroradiology 33:234-238.

8. Roccatagliata L, Bracard S, Holmin S, et al. (2013) Pediatric intracranial arteriovenous shunts: a global overview. Childs Nerv Syst ChNS Off J Int Soc Pediatr Neurosurg 29:907-919. doi: 10.1007/s00381-013-2114-8

9. Auyeung KM, Laughlin S, Terbrugge KG (2003) Prenatal diagnosis of unusual fetal pial arteriovenous malformation. A case report. Interv Neuroradiol J Peritherapeutic Neuroradiol Surg Proced Relat Neurosci 9:163-168.

10. Garel C, Azarian M, Lasjaunias P, Luton D (2005) Pial arteriovenous fistulas: dilemmas in prenatal diagnosis, counseling and postnatal treatment. Report of three cases. Ultrasound Obstet Gynecol Off J Int Soc Ultrasound Obstet Gynecol 26:293-296. doi: 10.1002/uog.1957

11. Köroğlu M, Cil B, Yeşildağ A, et al. (2006) Prenatal diagnosis of intracranial pial arteriovenous fistula and endovascular treatment during the neonatal period. Diagn Interv Radiol Ank Turk 12:64-67.

12. Paladini D, Palmieri S, D'Angelo A, Martinelli P (1996) Prenatal ultrasound diagnosis of cerebral arteriovenous fistula. Obstet Gynecol 88:678-681.

13. Di Rocco C, Tamburrini G, Rollo M (2000) Cerebral arteriovenous malformations in children. Acta Neurochir (Wien) 142:145-156; discussion 156-158. 
14. Yeo JJY, Low SYY, Seow WT, Low DCY (2014) Pediatric de novo cerebral AVM: report of two cases and review of literature. Childs Nerv Syst ChNS Off J Int Soc Pediatr Neurosurg. doi: 10.1007/s00381-014-2609-y

15. Chen W, Sun Z, Han Z, et al. (2014) De novo cerebrovascular malformation in the adult mouse after endothelial Alk1 deletion and angiogenic stimulation. Stroke J Cereb Circ 45:900-902. doi: 10.1161/STROKEAHA.113.003655

16. Choi E-J, Chen W, Jun K, et al. (2014) Novel brain arteriovenous malformation mouse models for type 1 hereditary hemorrhagic telangiectasia. PloS One 9:e88511. doi: 10.1371/journal.pone.0088511

17. Morales-Valero SF, Bortolotti C, Sturiale CL, Lanzino G (2014) Are parenchymal AVMs congenital lesions? Neurosurg Focus 37:E2. doi: 10.3171/2014.6.FOCUS14234

18. Murphy PA, Kim TN, Huang L, et al. (2014) Constitutively active Notch4 receptor elicits brain arteriovenous malformations through enlargement of capillary-like vessels. Proc Natl Acad Sci U S A 111:18007-18012. doi: 10.1073/pnas. 1415316111

19. ZhuGe Q, Wu Z, Huang L, et al. (2013) Notch4 is activated in endothelial and smooth muscle cells in human brain arteriovenous malformations. J Cell Mol Med 17:1458-1464. doi: 10.1111/jcmm.12115

20. Gailloud P, San Millán Ruíz D, Muster M, et al. (2000) Angiographic anatomy of the laterocavernous sinus. AJNR Am J Neuroradiol 21:1923-1929.

21. Lasjaunias P, Berenstein A, Ter Brugge KG (2001) Chapter 7: Intracranial Venous System. In: Surg. Neuro-Angiogr., 2nd ed. Springer Berlin Heidelberg, pp 631-713

22. Landis JR, Koch GG (1977) The measurement of observer agreement for categorical data. Biometrics 33:159-174.

23. Davidson AS, Morgan MK (2011) The embryologic basis for the anatomy of the cerebral vasculature related to arteriovenous malformations. J Clin Neurosci Off J Neurosurg Soc Australas 18:464-469. doi: 10.1016/j.jocn.2010.12.004

24. San Millán Ruíz D, Fasel JHD, Rüfenacht DA, Gailloud P (2004) The sphenoparietal sinus of breschet: does it exist? An anatomic study. AJNR Am J Neuroradiol 25:112-120.

25. San Millán Ruiz D, Gailloud P, de Miquel Miquel MA, et al. (1999) Laterocavernous sinus. Anat Rec 254:7-12.

26. Wiebers DO, Whisnant JP, Huston J, et al. (2003) Unruptured intracranial aneurysms: natural history, clinical outcome, and risks of surgical and endovascular treatment. Lancet Lond Engl 362:103-110. 
27. Mullan S (1994) Reflections upon the nature and management of intracranial and intraspinal vascular malformations and fistulae. J Neurosurg 80:606-616. doi: 10.3171/jns.1994.80.4.0606

28. Walker EJ, Su H, Shen F, et al. (2011) Arteriovenous malformation in the adult mouse brain resembling the human disease. Ann Neurol 69:954-962. doi: 10.1002/ana.22348

29. Kim H, Su H, Weinsheimer S, et al. (2011) Brain arteriovenous malformation pathogenesis: a response-to-injury paradigm. Acta Neurochir Suppl 111:83-92. doi: 10.1007/978-3-7091-0693-8_14

30. Hofmeister C, Stapf C, Hartmann A, et al. (2000) Demographic, morphological, and clinical characteristics of 1289 patients with brain arteriovenous malformation. Stroke J Cereb Circ 31:1307-1310.

31. Lee K-W, Tsai F-Y, Chen W-L, et al. (2014) Intracranial venous hemodynamics and rupture of cerebral aneurysm. Neuroradiol J 27:703-709.

32. van der Schaaf IC, Velthuis BK, Gouw A, Rinkel GJE (2004) Venous drainage in perimesencephalic hemorrhage. Stroke J Cereb Circ 35:1614-1618. doi: 10.1161/01.STR.0000131657.08655.ce 


\section{Figure captions}

Fig. 1

DSA in a 36-year-old male with an unruptured right occipital brain AVM. Anteroposterior (AP) projections of the right ICA angiogram at arterial (a) and venous (b) phases and lateral projections at arterial (c) and venous (d) phases showing the right occipital brain AVM (white arrowhead) with deep venous drainage. Note the absence of the right superficial middle cerebral vein (SMCV)

\section{Fig. 2}

DSA in a 48-year-old male with a ruptured $3 \mathrm{~mm}$ left posterior communicating artery aneurysm. AP projections of the right ICA angiogram at arterial (a) and venous (b) phases showing termination of the right SMCV in a laterocavernous sinus (LCS) (white arrow) secondarily drained in the pterygoid plexus (PP) (double white arrows). Fusion of the AP projections of the right ICA angiogram at arterial and venous phases showing close proximity of the LCS (white arrow) and ICA (triple white arrows) (c). AP projections of the left ICA angiogram at arterial (d) and venous (e) phases showing termination of the left SMCV (black arrowhead) directly in the left CS (black arrow). Note the connection of the left CS (black arrow) to the right CS (double black arrows) through an intercavernous sinus (white arrowhead). Fusion of the AP projections of the right and left ICA angiograms at venous phase demonstrating contiguity of the right LCS (white arrow) and the right CS (double black arrows) (f) 


\section{Fig. 3}

DSA in a 47-year-old female with a ruptured anterior communicating artery aneurysm. AP projections of the left ICA angiogram at arterial (a) and venous (b) phases showing termination of the left SMCV (white arrow) in a paracavernous sinus (PCS) (white arrowhead). c: Fusion of the AP projections of the left ICA angiogram at arterial and venous phases showing distance separating the PCS (white arrowhead) from the ICA (black arrowhead). Lateral projections of the left ICA angiogram at arterial (d) and venous (e) phases showing termination of the left SMCV (white arrow) in a PCS (white arrowhead) secondarily drained into the tentorial sinus (black arrow) and lateral sinus. f: Fusion of the lateral projections of the left ICA angiogram at arterial and venous phases showing the distance separating the PCS (white arrowhead) from the ICA (black arrowhead)

\section{Fig. 4}

DSA in a 48-year-old female with a ruptured left orbitofrontal brain AVM. AP projections of the left ICA angiogram at early arterial (a) late arterial (b) and venous phases (c) showing the left orbitofrontal brain AVM (white arrow) drained in the left SMCV (white arrowhead) that terminates in the left CS (black arrow). Lateral projections of the left ICA angiogram at late arterial phase (d) showing the left SMCV (white arrowhead) terminating in the left CS (black arrow) that drains into the left inferior petrosal sinus (black arrowhead) 
Table 1. Comparison of SMCV's anatomy in patients with a brain AVM and controls

\begin{tabular}{|c|c|c|c|c|}
\hline & $\begin{array}{c}\text { Overall } \\
\text { population (144 } \\
\text { patients; } n= \\
250)\end{array}$ & $\begin{array}{l}\text { Brain AVM group } \\
\qquad \begin{array}{l}\text { (70 patients; } \\
n=125)\end{array}\end{array}$ & $\begin{array}{c}\text { Control group (74 } \\
\text { patients; } \\
n=125)\end{array}$ & $p$-value \\
\hline $\begin{array}{l}\text { Mean age }+/- \text { standard } \\
\text { deviation (years) }\end{array}$ & $45 \pm 15$ & $41 \pm 15$ & $50 \pm 13$ & $<10^{-4 \ddagger}$ \\
\hline Male sex (\%) & $58(40)$ & $36(51)$ & $22(30)$ & 0.007 \\
\hline $\begin{array}{l}\text { Hemorrhagic presentation } \\
(\%)\end{array}$ & $99(68.7)$ & $54(77.1)$ & $45(60.8)$ & 0.03 \\
\hline SMCV present (\%) & $184(73.6)$ & $88(70.4)$ & $96(76.8)$ & 0.25 \\
\hline Multiple SMCV (\%) & $50(20)$ & $21(16.8)$ & $29(23.2)$ & 0.20 \\
\hline $\begin{array}{l}\text { Direct or indirect } \\
\text { connection of the SMCV } \\
\text { to the CS }(\%)\end{array}$ & $130(52)$ & $65(52)$ & $65(52)$ & 1 \\
\hline $\begin{array}{l}\text { SMCV terminating into a } \\
\text { LCS }(\%)\end{array}$ & $75(30)$ & $44(35.2)$ & $31(24.8)$ & 0.07 \\
\hline $\begin{array}{l}\text { Drainage of the } \\
\text { LCS in the CS (\%) }\end{array}$ & $68(90.6)$ & $40(90.9)$ & $28(90.3)$ & $1^{*}$ \\
\hline $\begin{array}{l}\text { Drainage of the } \\
\text { LCS in the SPS or } \\
\text { tentorial sinus (\%) }\end{array}$ & $8(10.6)$ & $7(15.9)$ & $1(3.2)$ & $0.12^{*}$ \\
\hline $\begin{array}{l}\text { Drainage of the } \\
\text { LCS in the PP (\%) }\end{array}$ & $35(46.6)$ & $21(47.7)$ & $14(45.1)$ & 0.82 \\
\hline
\end{tabular}




\begin{tabular}{|c|c|c|c|c|}
\hline SMCV terminating into a & $70(28)$ & $27(21.6)$ & $43(34.4)$ & 0.02 \\
\hline Drainage of the & $25(35.7)$ & $9(33.3)$ & $16(37.2)$ & 0.74 \\
PCS in the CS (\%) & & $11(40.7)$ & $16(37.2)$ & 0.76 \\
\hline Drainage of the & & & \\
\hline PCS in the SPS or & $27(38.5)$ & $22(81.4)$ & $34(79.0)$ & 0.80 \\
\hline tentorial sinus (\%) & & & \\
\hline Drainage of the & $56(80)$ & $17(13.6)$ & $22(17.6)$ & 0.38 \\
\hline PCS in the PP (\%) & & & \\
\hline SMCV terminating directly \\
into the CS (\%)
\end{tabular}

$\mathrm{n}$ is the total number of sides analyzed for each group; numbers in brackets are percentages

The $p$-values are for comparison of the brain AVM and control groups.

*: Fisher's Exact Test

‡: Student's $t$-test

Abbreviations: Cavernous Sinus (CS) ; Laterocavernous Sinus (LCS) ; Paracavernous Sinus (PCS) ; Pterygoid Plexus (PP) ; Superficial Middle Cerebral Vein (SMCV) 
Table 2. Comparison of SMCV's anatomy in patients with an ipsilateral supratentorial brain AVM and controls

\begin{tabular}{|c|c|c|c|}
\hline & $\begin{array}{l}\text { Brain AVM group (53 } \\
\text { patients; } n=53 \text { ) }\end{array}$ & $\begin{array}{l}\text { Control group }(74 \\
\text { patients; } n=125)\end{array}$ & $p$-value \\
\hline Right-Side (\%) & $27(50.9)$ & $65(52)$ & 0.89 \\
\hline Left-Side (\%) & $26(49.0)$ & $60(48)$ & 0.89 \\
\hline $\begin{array}{l}\text { Mean age }+/- \\
\text { standard } \\
\text { (years) }\end{array}$ & $38 \pm 13$ & $50 \pm 13$ & $<10^{-4} \ddagger$ \\
\hline Male sex (\%) & $28(53)$ & $22(30)$ & 0.008 \\
\hline $\begin{array}{l}\text { Hemorrhagic } \\
\text { presentation (\%) }\end{array}$ & $40(75.5)$ & $45(60.8)$ & 0.08 \\
\hline SMCV present (\%) & $38(71.6)$ & $96(76.8)$ & 0.47 \\
\hline Multiple SMCV (\%) & $10(18.8)$ & $29(23.2)$ & 0.52 \\
\hline $\begin{array}{l}\text { Direct or indirect } \\
\text { connection of the } \\
\text { SMCV to the CS }(\%)\end{array}$ & $26(49.0)$ & $65(52)$ & 0.71 \\
\hline $\begin{array}{l}\text { SMCV terminating } \\
\text { into a LCS }(\%)\end{array}$ & $17(32.0)$ & $31(24.8)$ & 0.31 \\
\hline $\begin{array}{l}\text { Drainage of } \\
\text { the LCS in the } \\
\text { CS (\%) }\end{array}$ & $15(88.2)$ & $28(90.3)$ & $1^{*}$ \\
\hline $\begin{array}{l}\text { Drainage of } \\
\text { the LCS in the } \\
\text { SPS or } \\
\text { tentorial sinus } \\
(\%)\end{array}$ & $2(11.7)$ & $1(3.2)$ & $0.28^{*}$ \\
\hline $\begin{array}{l}\text { Drainage of } \\
\text { the LCS in the } \\
P P(\%)\end{array}$ & $9(52.9)$ & $14(45.1)$ & 0.60 \\
\hline $\begin{array}{l}\text { SMCV terminating } \\
\text { into a PCS }(\%)\end{array}$ & $15(28.3)$ & $43(34.4)$ & 0.42 \\
\hline $\begin{array}{l}\text { Drainage of } \\
\text { the PCS in the } \\
C S(\%)\end{array}$ & $6(40)$ & $16(37.2)$ & 0.84 \\
\hline $\begin{array}{l}\text { Drainage of } \\
\text { the PCS in the } \\
\text { SPS or } \\
\text { tentorial sinus }\end{array}$ & $5(33.3)$ & $16(37.2)$ & 0.78 \\
\hline
\end{tabular}




\begin{tabular}{|c|l|l|l|}
\hline (\%) & & \\
\hline $\begin{array}{l}\text { Drainage of } \\
\text { the PCS in the } \\
\text { PP (\%) }\end{array}$ & $12(80)$ & $1^{*}$ \\
\hline $\begin{array}{l}\text { SMCV terminating } \\
\text { directly into CS (\%) }\end{array}$ & $6(11.3)$ & $22(17.6)$ & 0.29 \\
\hline
\end{tabular}

$\mathrm{n}$ is the total number of sides analyzed for each group; numbers in brackets are percentages

*: Fisher's Exact Test

‡: Student's $t$-test

Abbreviations: Cavernous Sinus (CS) ; Laterocavernous Sinus (LCS) ; Paracavernous Sinus (PCS) ; Pterygoid Plexus (PP) ; Superficial Middle Cerebral Vein (SMCV) 

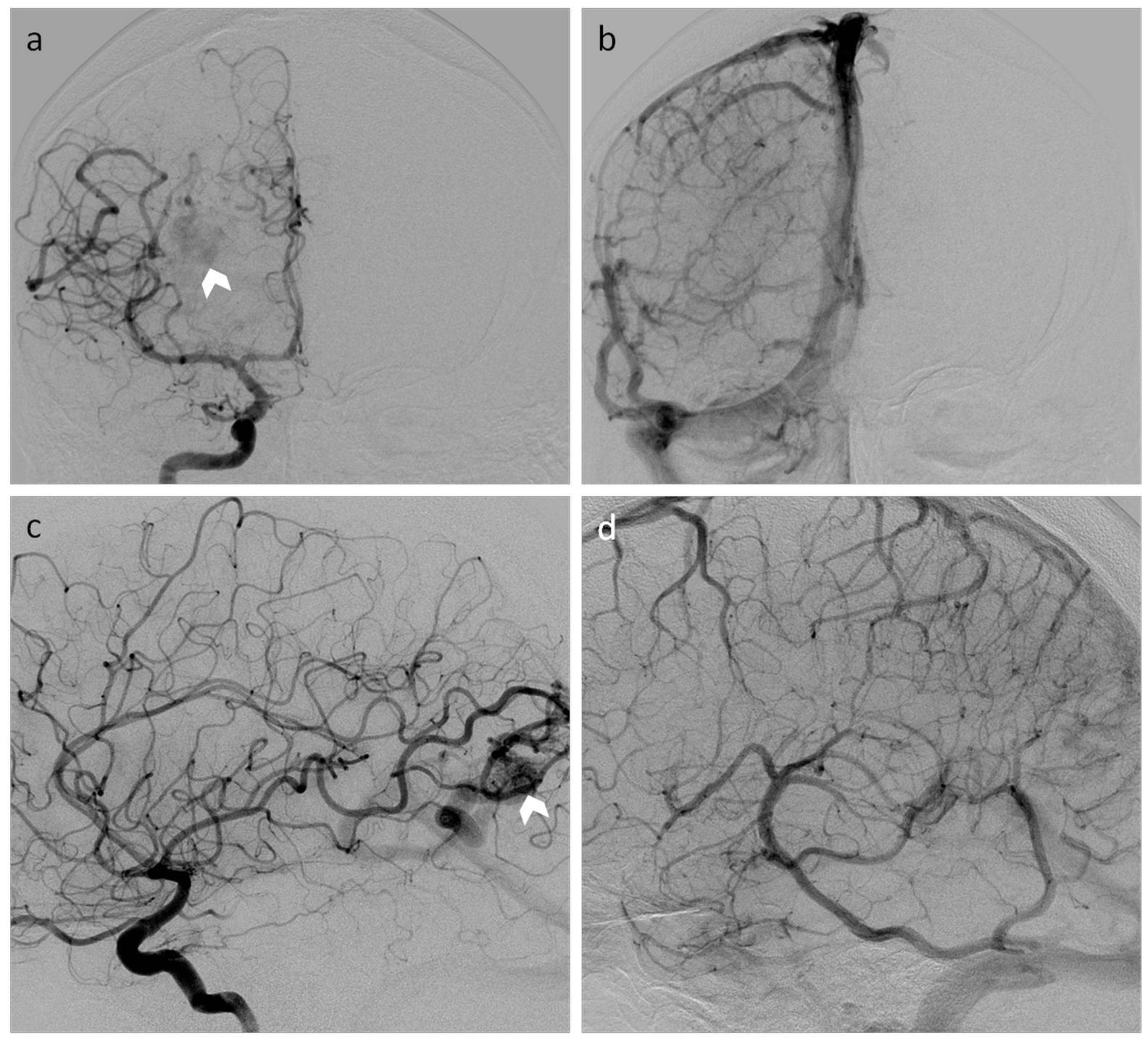

Fig. 1 

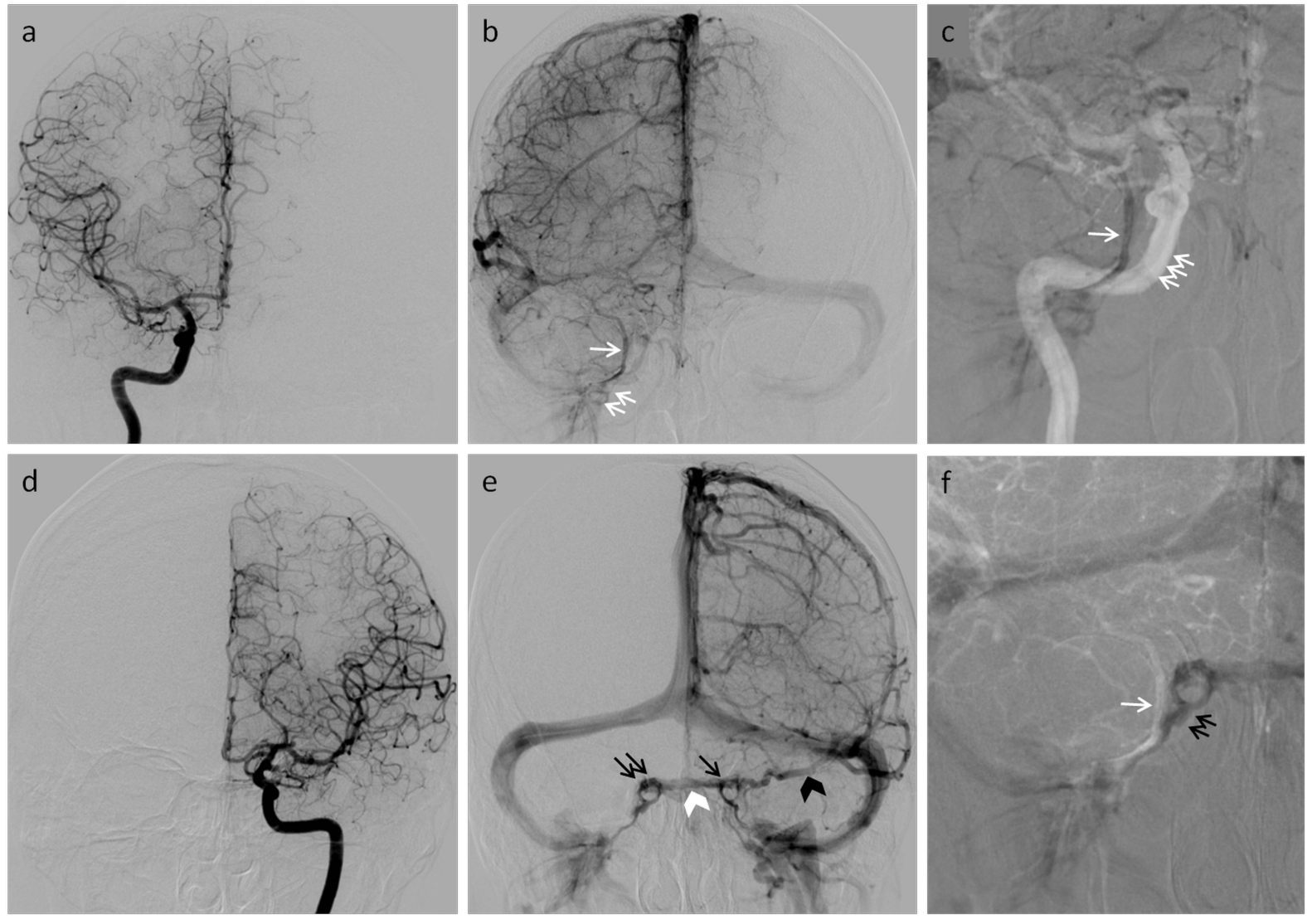

Fig. 2 

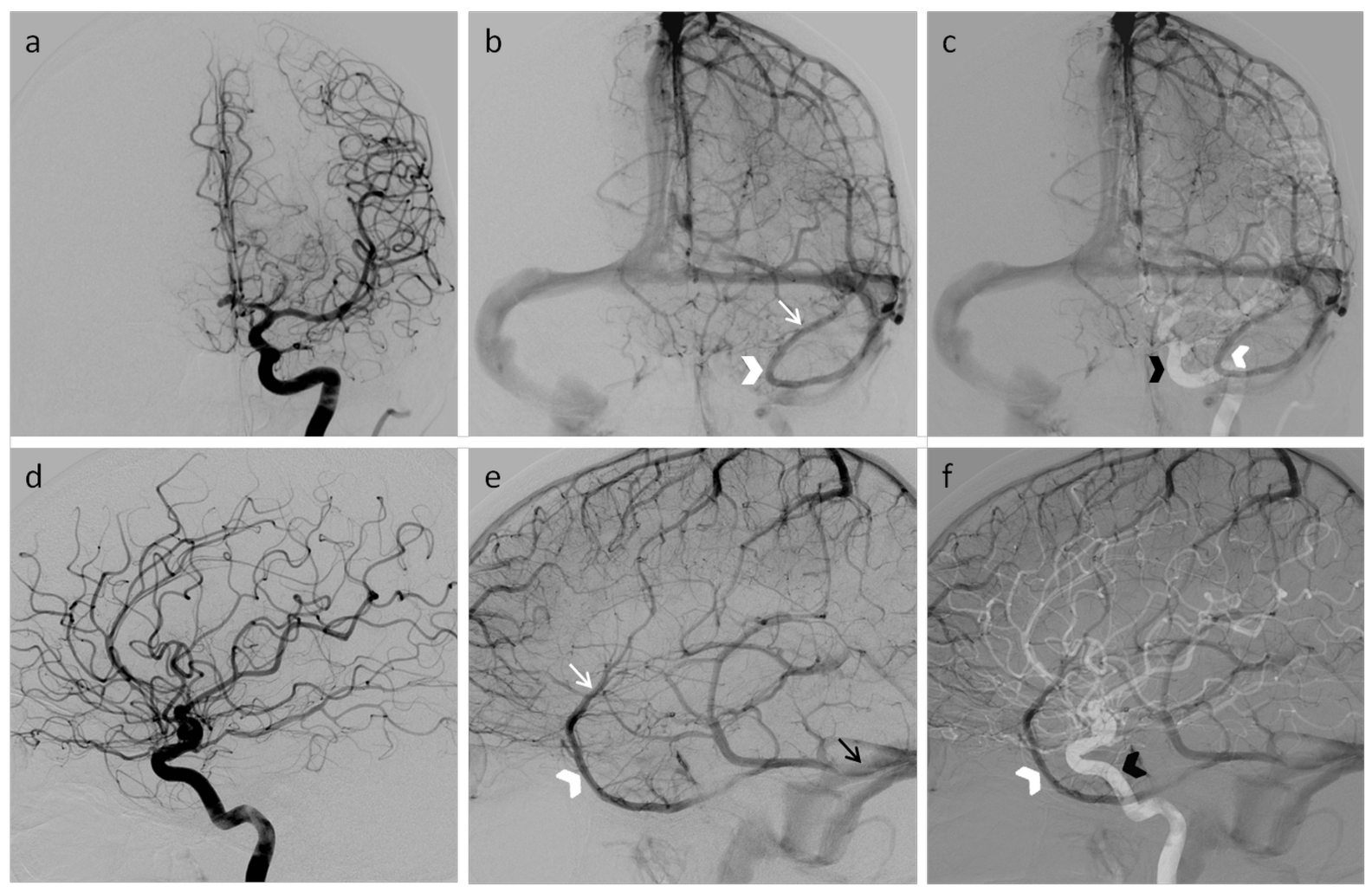

Fig. 3 

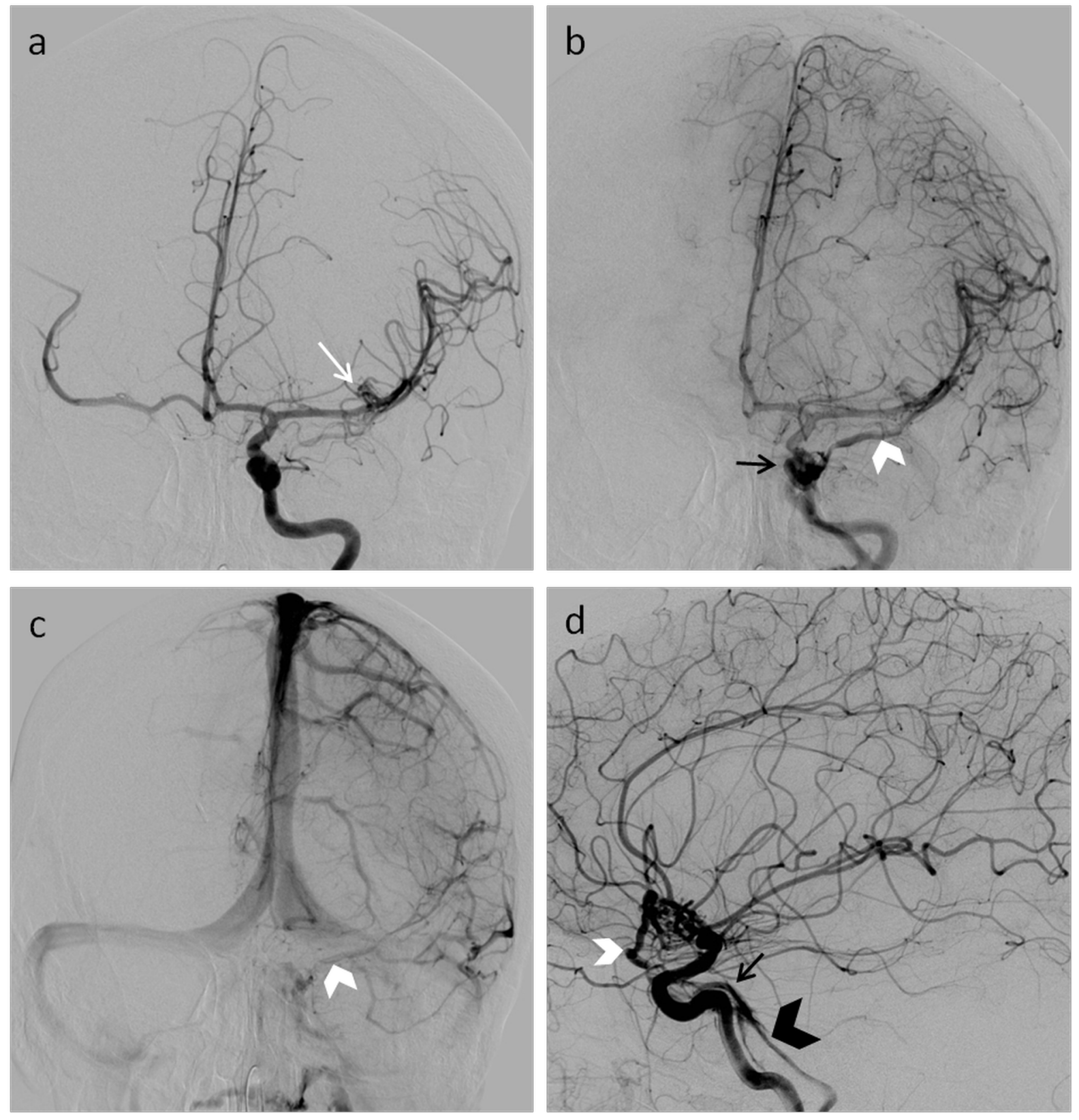

Fig. 4 